\title{
Enterprise Vocabulary
}

National Cancer Institute

\section{Source}

National Cancer Institute. Enterprise Vocabulary. NCI Thesaurus. Code C43528.

A listing of the words used in some enterprise. 